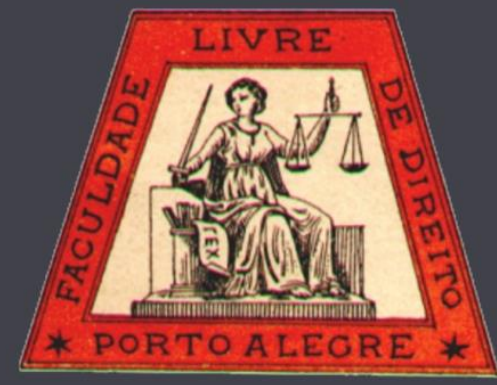

\title{
O trabalho infantil indígena sancionado pela diversidade cultural
}

Indigenous child labor sanctioned by cultural diversity

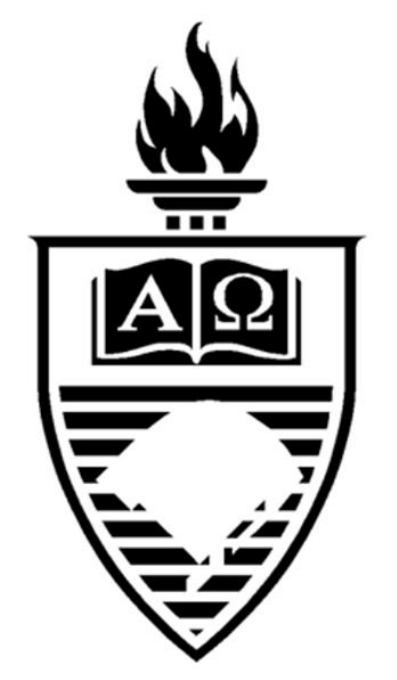

\author{
Fernanda Marders \\ Centro Universitário Univates \\ Suzéte da Silva Reis \\ Universidade de Santa Cruz do Sul
}

\section{UFRGS}




\title{
O trabalho infantil indígena sancionado pela diversidade cultural
}

\author{
Indigenous child labor sanctioned by cultural diversity
}

Fernanda Marders*

Suzéte da Silva Reis ${ }^{* *}$

\begin{abstract}
REFERÊNCIA
MARDERS, Fernanda; REIS, Suzéte da Silva. O trabalho infantil indígena sancionado pela diversidade cultural. Revista da Faculdade de Direito da UFRGS, Porto Alegre, n. 34, p. 218-237, ago. 2016.
\end{abstract}

\begin{abstract}
RESUMO
Este estudo, desenvolvido por meio de análise bibliográfica e documental, abordará, primeiramente, a relação do princípio da igualdade no mundo do direito do trabalho para, posteriormente, desenvolver a contínua ocorrência do trabalho infantil, ao longo do tempo e nos dias atuais, desrespeitando a máxima proteção inerente às crianças, conforme garantido no texto constitucional e nas demais legislações. Será necessário desenvolver esse contexto histórico para que seja possível adentrar na questão cultural, que se utiliza como base de autorização para o trabalho infantil indígena, fazendo com que essas crianças sejam discriminadas e que a teoria da proteção integral não seja a elas alcançada. É intuito desse trabalho demonstrar que o trabalho infantil continua a acontecer, inclusive no mundo indígena, mas que faz-se necessário que todas as formas de trabalho infantil sejam erradicadas e que não se conceda, de forma alguma ou em hipótese alguma, objeções que permitam que o trabalho infantil ocorra.
\end{abstract}

\section{PALAVRAS-CHAVE}

Diferença cultural. Princípio da Igualdade. Proteção Integral. Trabalho infantil indígena.

\begin{abstract}
This study, carried out through bibliographical and documentary analysis, will address, first, the relationship of the principle of equality in the labor law environment, in order to subsequently develop the continued occurrence of child labor, over time and in these days, disregarding the maximum protection inherent to children as granted in the Constitution and in other legislation. It will be necessary to develop this historical context in order to approach the cultural question, which is used as basis for authorization of the indigenous child labor, making these children discriminated against and not letting the theory of full protection to achieve them. It is the purpose of this study to demonstrate that child labor continues to happen, even in the indigenous environment, but it is necessary to eradicate all forms of child labor and that should not be granted, in any way or under any circumstances, objections that allow child labor to occur.
\end{abstract}

\section{KEYWORDS}

Cultural difference. Principle of equality. Integral protection. Indigenous child labor.

\section{SUMÁRIO}

\footnotetext{
* Professora Assistente do Centro Universitário Univates. Mestra em Direitos Humanos (Universidade do Minho Portugal, 2016). Mestra em Direito (Universidade de Santa Cruz do Sul - UNISC, 2015). Especialista em Direito e Processo do Trabalho (Centro Universitário Univates, 2016). Graduada em Direito (Centro Universitário Univates, 2013) e em Ciências Contábeis (Centro Universitário Univates, 2008). Investigadora colaboradora do Centro de Investigação Interdisciplinar em Direitos Humanos da Escola de Direito da Universidade do Minho de Portugal. Advogada.

${ }^{* *}$ Professora de Direito do Trabalho e Processual do Trabalho da Universidade de Santa Cruz do Sul (UNISC). Doutora em Direito (Universidade de Santa Cruz do Sul - UNISC, 2015). Mestre em Direito na área de Políticas Públicas de Inclusão Social (Universidade de Santa Cruz do Sul - UNISC, 2011). Especialista em Direito do Trabalho, Previdenciário e Processo do Trabalho (Universidade de Santa Cruz do Sul - UNISC, 2009) e em Informática Aplicada à Educação (Universidade de Santa Cruz do Sul - UNISC, 1997). Graduada em Direito (Universidade de Santa Cruz do Sul UNISC, 2008) e em Pedagogia (Faculdades Integradas de Santa Cruz do Sul - FISC, 1990). Membro dos Grupos de Pesquisa "Direito, Cidadania e Políticas Públicas" e "Direitos Humanos de Crianças, Adolescentes e Jovens", ligados ao Programa de Pós-Graduação em Direito da UNISC. Advogada.
} 
Introdução. 1. O direito do trabalho com fundamento no princípio da igualdade. 2. A proteção integral à criança e ao adolescente e a abolição do trabalho infantil. 3. O trabalho das crianças indígenas com base na cultura da comunidade. Conclusão. Referências.

\section{INTRODUÇÃO}

O trabalho infantil há muito é tema de discussão; no entanto, não adianta somente a discussão de possíveis medidas, faz-se necessário que essas saiam do papel para serem aplicadas de modo eficaz na vida concreta. Muitos projetos legislativos são criados, mas uma boa parte deles perde eficácia antes mesmo de ser votado. Planos de erradicação do trabalho infantil são criados, mas abrem-se brechas para que determinados grupos de crianças possam trabalhar, fazendo com que a proteção integral da criança seja esquecida e aplicada a grupos restritos.

Nesse enfoque, o princípio da igualdade, constante na Constituição Federal de 1988, torna-se, simplesmente, texto de lei sem eficácia e, juntamente com a dignidade da pessoa humana, mais parece um enfeite constitucional que não alcança todos os seres humanos.

Sendo assim, com um pensamento voltado para a máxima proteção da criança que esse artigo vem defender a igual proteção para toda a infância incluindo, dessa forma, também as crianças indígenas. Não é possível que no século XXI se autorize que qualquer criança seja utilizada como mão de obra rentável para que a família tenha garantida uma melhora na sua condição financeira.

Tão pouco é possível que se utilize das características culturais de um povo para justificar o trabalho infantil das crianças indígenas. Devemos sim, respeitar os aspectos culturais dos índios na medida em que estes não prejudiquem o próprio ser humano e, nesse caso, a própria criança que dará continuidade as belas tradições desse povo.

Dessa forma, esse artigo foi elaborado com base bibliográfica e documental e está dividido em três capítulos que buscam trazer aspectos relevantes sobre o trabalho da criança indígena e com isso estabelecer que o conceito de cultura, ao qual se utiliza como base para a autorização do trabalho infantil, não almeja explorar ou violentar (de qualquer forma) aqueles que a seguem. Para iniciar abordar-se-á o princípio da igualdade e sua relevância no mundo do direito do trabalho, sobre o qual se passa a tratar.

\section{O DIREITO DO TRABALHO COM FUNDAMENTO NO PRINCÍPIO DA IGUALDADE}

A igualdade é um dos princípios dos direitos humanos com maior prestígio, contudo, defini-la é uma tarefa árdua. Foi na Revolução Francesa de 1789 que se instaurou uma luta para que fosse posto fim as desigualdades individuais e coletivas. Com o intuito de acabar com os privilégios individuais, a Declaração dos Direitos do Homem e do Cidadão de 1789 preconizava a igualdade concreta entre os seres humanos. Esse entendimento jurídico foi sendo alterado ao longo do tempo e hoje se pode considerar " [...] que a igualdade constitui o signo fundamental da democracia" (SILVA, 2014, p. 213).

No entanto, apesar de a Declaração ter estampado a tríade liberdade, igualdade e fraternidade, o que se observou foi um esquecimento das duas últimas para se dar enfoque à ideais de liberdade que mantinham o poder da burguesia e o comando da sociedade 
suscetível aos seus mandos; assim, as relações de trabalho se estabeleciam com base no interesse da classe que detinha o poder econômico, fazendo com que os trabalhadores fossem explorados a exaustão e submetidos a condições de desigualdade.

Contudo, cabe mencionar que mesmo em meio a exploração humana que se vivia, a Declaração iniciou o processo de construção do conceito de isonomia até chegarmos as formas que essa está posta na atualidade. No presente, a doutrina estabelece uma diferenciação entre a igualdade formal e a igualdade material, sendo que, as constituições somente têm admitido a isonomia jurídico-formal, ou seja, igualdade perante a lei (SILVA, 2014).

A igualdade material "[...] visa assegurar tratamento equânime e uniforme de todos os seres humanos, assim por dizer, no tratamento equiparado na possibilidade de acesso a todos os bens da vida, proporcionando, dessa forma, a igualdade real e efetiva de todos" (LEITE, 2011, p. 50), ou seja, é a concretização da igualdade formal, advinda da legislação vigente, na vida diária do homem que compõe uma sociedade.

Ademais, conforme Canotilho (2014, p. 426) "ser igual perante a lei não significa apenas aplicação igual da lei. A lei, ela própria, deve tratar por igual todos os cidadãos. O princípio da igualdade dirige-se ao próprio legislador, vinculando-o à criação de um direito igual para todos os cidadãos", fazendo com que o princípio da isonomia cumpra o papel fundamental de fazer justiça na vida humana e implique na inconstitucionalidade da lei quando o legislador não buscar por meio da sua criação alcançar equidade a todos.

Com base no alcance da isonomia de forma plena, para todos os brasileiros e estrangeiros, que a CF no art. $5^{\circ}$, caput, estabelece que todos são iguais diante da lei sem que se possa discrimina-las de qualquer forma, sendo-lhes garantido o direito à vida, à liberdade, à igualdade, à segurança e à propriedade. $\mathrm{O}$ mesmo entendimento se estabelece no meio laboral, onde os trabalhadores também devem ser tratados com observância ao princípio da isonomia, ao qual preconiza que todos devem ser tratados de forma igual ao mesmo tempo em que se observa a desigualdade existente entre os indivíduos, ou seja, "[...] independente do problema da distinção entre 'igualdade fáctica' e 'igualdade jurídica' e dos problemas econômicos e políticos ligados à primeira, o princípio da igualdade pode e deve considerar-se um princípio de justiça social" (CANOTILHO, 2014, p. 430, grifos do autor).

Dessa forma, realizar-se-á a igualdade de modo a estabelecer uma isonomia que garanta a dignidade humana, não importando a classe social ou qualquer outro tipo de diferença que exista, concretizando além do princípio da igualdade, posto em nosso texto constitucional, o princípio da dignidade da pessoa humana (art. $1^{\circ}$, inciso III, da CF).

Tal premissa de igualdade é refletida na atualidade por meio de ações afirmativas e discriminações negativas, pois em determinados momentos faz-se necessário que alguns grupos sociais sejam tratados de maneira diferente para suprimir marginalizações por esses sofridas. Assim, por meio das ações afirmativas se pretende equilibrar $o$ tratamento entre os favorecidos e os desfavorecidos, concretizando a ambos uma vida de real dignidade e sem qualquer limitação, ou seja, busca-se nivelar possíveis injustiças oriundas da desigualdade sem respaldo constitucional ocasionada por alguém sobre outrem que caracteriza as discriminações negativas.

A legislação portuguesa, por sua vez, preconiza a diferenciação entre a discriminação direta e discriminação indireta. Nesse sentido, segundo o art. 23 do Código do Trabalho (CT), a discriminação direta sempre irá ocorrer quando determinada pessoa é ou poderá vir a ser exposta 
a um tratamento menos apropriado do que outro indivíduo; enquanto que a discriminação indireta será caracterizada, de acordo com a Directiva 2000/78/CE,

\begin{abstract}
sempre que uma disposição, critério ou prática aparentemente neutra seja susceptível de colocar numa situação de desvantagem pessoas com uma determinada religião ou convicções, com uma determinada deficiência, pessoas de uma determinada classe etária ou pessoas com uma determinada orientação sexual, comparativamente com outras pessoas (PORTUGAL, 2000).
\end{abstract}

Ainda, nesse sentido, deve-se fazer referência a Convenção n. 111 da Organização Internacional do Trabalho (OIT, 1960), ratificada pelo Brasil em 26 de novembro de 1995 e promulgada pelo Decreto n. 62.150 em 19 de janeiro de 1968, que estabelece - com base na Declaração da Filadélfia, para qual todos os seres humanos são iguais independente de raça, credo e sexo, devendo ser garantido de modo amplo a todos o seu desenvolvimento material e espiritual com liberdade e dignidade - que "toda distinção, exclusão ou preferência fundada na raça, cor, sexo, religião, opinião política, ascendência nacional ou origem social, que tenha por efeito destruir ou alterar a igualdade de oportunidade ou de tratamento em matéria de emprego ou profissão" (art. 1, "a").

Corrobora Silva (2014, p. 230) ao mencionar que "são inconstitucionais as discriminações não autorizadas pela Constituição. $\mathrm{O}$ ato discriminatório é inconstitucional". Nesse sentido, duas são as hipóteses de inconstitucionalidade apresentadas. A primeira ocorre quando se oferta um benefício a determinado grupo de maneira a descriminá-los favoravelmente em detrimento de outrem em idêntica situação e "a outra forma de inconstitucionalidade revela-se em se impor obrigação, ônus, sanção ou qualquer sacrifício a pessoas ou grupo, discriminando-as em face de outros na mesma situação que, assim, permaneceram em condições mais favoráveis" (SILVA, 2014, p. 231).

Nota-se assim, que todas as pessoas merecem ter sua dignidade respeitada, independente de sexo, cor, raça, idade, credo social etc., não sendo possível, nesse contexto, que se admita o contrário no que tange as relações de trabalho e no que envolve o trabalho de crianças indígenas. Como salienta Rawls (2008, p. 75) "todos os valores sociais liberdade e oportunidade, renda e riqueza, e as bases sociais do autorrespeito - devem ser distribuídos de forma igual, a não ser que uma distribuição desigual de um ou de todos esses valores seja vantajosa para todos".

Dessa forma, não se pode admitir que a classe trabalhadora, considerada hipossuficiente pois dedica o seu corpo e sua alma para o empresariado, seja explorada em troca de um papel moeda, muito mais forte e impactante em toda a economia mundial nos dias atuais. Ademais, no que tange as crianças, estas também são consideradas hipossuficientes, pois ainda não tem o total discernimento necessário para a vida adulta, devendo-lhes ser garantido total e integral proteção.

São esses dois grupos que se alcança nesse trabalho, as crianças e os trabalhadores, uma vez que se admite no cenário brasileiro que as crianças indígenas trabalhem juntamente com os seus pais para prover o sustento familiar e da comunidade em que estão inseridas. Tal permissividade acarreta em tratamento desigual com relação às outras crianças. Nesse sentido, está a se operar uma desigualdade entre as crianças com base na cultura de cada uma, pois é autorizado o trabalho das crianças indígenas enquanto que outras crianças, em uma situação de pobreza idêntica aquelas não podem trabalhar para ajudar a prover o sustento da família. O tratamento desigual de dois grupos nesse cenário, ao invés de favorecer e apontar para um possível equilíbrio, acaba por prejudicar a 
dignidade das crianças indígenas.

Nota-se que o trabalhador sempre esteve em realce no mundo uma vez que é por meio do labor que a maioria retira o sustento de uma vida guiada pelo capitalismo enquanto que a criança, como bem menciona Custódio (2006, p. 19), foi ocupando lugares diversos no desenrolar da história, sendo " [...] órfã, abandonada, delinquente, escrava, menor, trabalhadora; mas também pura, ingênua, bela e até promessa de futuro".

Pensando em um bem maior para o futuro da nossa geração e para que não se estabeleça formas de burlar a proteção infantil que se adota na atualidade a proteção integral da criança, a qual não será alcançada no caso das crianças indígenas, pois se está a abrir um precedente para que há um grupo seja concedido e permitido o trabalho infantil, assunto que será melhor analisado a seguir.

\section{A PROTEÇÃO INTEGRAL À CRIANÇA E AO ADOLESCENTE E A ABOLIÇÃO DO TRABALHO INFANTIL}

$\mathrm{Na}$ história de vários, talvez todos os países do mundo, a criança e o adolescente estiveram presentes no desenvolver do direito do trabalho como seres humanos explorados, geradores de mão de obra barata. Foram as crianças, juntamente com as mulheres, que suportaram a I Guerra Mundial na Alemanha, pois erram elas que produziam nas fábricas a munição utilizada pelos soldados e os alimentos necessários para a sua sobrevivência e daqueles que lutavam.

Contudo, muito antes da primeira Guerra já se observava a exploração infantil; nesse sentido, de acordo com Süssekind et al (2005, p. 1007),

talvez seja no Código de Hamurabi, que data de 2000 anos antes de Cristo, que encontraremos as primeiras medidas de proteção aos menores, que trabalhavam como aprendizes. Com efeito, o
Código de Hamurabi previa que se um artesão tomasse algum menor para criar como filho adotivo, deveria ensinar-lhe seu ofício. Se lho ensinasse, o filho adotivo não poderia mais ser reclamado por seus pais de sangue. Mas se não lhe ensinasse o ofício, o adotivo poderia voltar livremente para a casa de seu pai biológico.

Durante o século XII a XX perdurou no Egito as dinastias, nesse período exigia-se que todos os cidadãos, independentemente de classe econômica ou condição física, prestassem serviços; todos deveriam trabalhar a partir do momento que apresentassem algum desenvolvimento físico. $\mathrm{Na}$ Grécia Antiga os filhos dos escravos laboravam para os senhores em benefício de seus pais. Já na Idade Média as crianças trabalhavam nas corporações de ofício e quando essas foram extintas pela Lei Chapelier em 1791, as máquinas absorveram a mão de obra infantil, considerada de baixo custo e "dócil", pois não reivindicava nenhuma melhoria em sua condição e laboravam de 14 a 16 horas diárias.

Conforme Barros (2011, p. 433) "a dificuldade econômica das famílias tem sido a principal responsável pela exploração de que são vítimas os menores, desde a primeira infância e nas mais variadas épocas da humanidade". Sendo assim, percebe-se que há muitos séculos já se vem travando uma batalha para que o trabalho infantil seja protegido e erradicado do meio social. Nesse sentido, em torno do século XIX, em diversos países, redigiu-se uma legislação que fosse protetiva e que estabelecesse limites na contratação de crianças e adolescentes.

Desde a Conferência de Berlin, de março de 1890 ,
já se estudavam as bases para a regulamentação
internacional do trabalho do menor, deixando clara
a necessidade de intervenção estatal nesta área. A
legislação sobre o trabalho do menor sofreu a
influência da ação internacional, recebendo um
tratamento nitidamente tutelar (BARROS, 2011, p.
436).

A Organização Internacional do Trabalho (OIT), desde a sua criação em 1919, já tem 
esboçado preocupação com relação ao trabalho infantil, isso é demonstrado já em sua primeira Conferência ocorrida ainda em 29 de outubro de 1919, na qual, estabeleceu as Convenções n. 5 e n. 6 , dentre outras, que trataram da idade mínima de admissão nos trabalhos industriais. Além dessas duas, a OIT tem outras Convenções as quais se destaca as de n. 16, 58, 138,142 que foram ratificadas pelo Brasil. Além de Convenções a OIT ainda tem Recomendações que versam sobre essa temática, tudo isso de modo a combater a exploração das crianças e adolescentes.

Cabe ressaltar que, no direito interno já se via a preocupação com o tema ao final do século XIX. Nosso país tentava se colocar em favor da proteção infantil ocasionada por meio do Decreto 1.313, de 17 de janeiro de 1891, que estabeleceu a regulamentação quanto a exploração da mão de obra de crianças e adolescentes que ocorriam em fábricas do Rio de Janeiro (SOUZA, 2008).

Entre outras medidas, o citado regulamento dispunha que os menores do sexo feminino de 12 a 15 anos e os do sexo masculino de 12 a 14 anos só poderiam trabalhar, no máximo, sete horas por dia, não consecutivas, de modo que nunca excedesse a quatro horas de trabalho contínuo; e os do sexo masculino de 14 a 15 anos, até nove horas por dia, nas mesmas condições. Os menores aprendizes que nas fábricas de tecido poderiam ser admitidos desde oito anos - só trabalhavam três horas (MORAES FILHO; MORAES, 2014, p. 429).

Posterior a esse Decreto, várias outras regulamentações surgiram com o intuito de proteger crianças e adolescentes que laboravam nas fábricas, contudo, "e assim era em quase todo o mundo: muitas leis não cumpridas referindo-se aos menores que definhavam nas fábricas" (SÜSSEKIND et al, 2005, p. 1010). Foi somente no período da Primeira Guerra Mundial que se iniciou um processo de conscientização de que as medidas de proteção à infância deveriam se tornar realidade, não só no plano legislativo, mas também no plano prático.
O Brasil foi o primeiro país da América Latina a edificar um Código de Menores, que foi aprovado em 12 de outubro de 1927 por meio do Decreto n. 17.943-A. O texto garantia um limite de 12 anos de idade para o trabalho do menor além da proibição do trabalho noturno para menores de 18 anos e a prestação de labor em local público para aqueles com idade inferior a 14 anos (MORAES FILHO; MORAES, 2014). Essa normatização protetiva foi ampliada a partir do governo de Getúlio Vargas em 1930. Por meio do Decreto n. 22.042 de 3 de novembro de 1932 se garantia a proibição do trabalho do menor de 16 anos, assim como, determinou-se a prestação de contas por parte da empresa do número de empregados menores de idade.

Em 1934, a Constituição vedou o trabalho dos menores de 14 anos, sendo inovadora nessa questão uma vez que as Constituições de 1824 e 1891 nada abordaram sobre o tema. Esses dispositivos que vedavam o trabalho do menor de 14 anos continuaram a constar nas Constituições de 1937 e 1946, sendo alterado pela Constituição de 1967 que reduziu a idade para 12 anos, sendo esse o padrão seguido pela Emenda de 1969.

Em meio a estas Constituições, no ano de 1941, o Decreto-Lei n. 3.616, de 13 de setembro, foi considerado um importantíssimo instrumento na luta pela proteção do menor trabalhador, pois ampliava e aprimorava as disposições anteriores vigentes. Por meio desse foi criada, entre outras, a carteira de trabalho do menor (SÜSSEKIND et $a l, 2005)$.

Dois anos após, em 1 de maio de 1943, organizando todas as leis vigentes que versavam sobre o direito do trabalho, é aprovada a Consolidação das Leis do Trabalho por meio do Decreto-Lei n. 5.452. Esse diploma legal trouxe no Capítulo IV, Título III, em 39 artigos, a regulamentação das tutelas especiais e a proteção do trabalho do menor, sendo, em 1967 pelo Decreto n. 229, acrescentado o texto que 
disciplinava o que se entendia por menor. Assim a CLT, no art. 402 estabelecia: "considera-se menor para os efeitos desta Consolidação o trabalhador de 12 (doze) a 18 (dezoito) anos" (BRASIL, 1943).

Ao passo da Constituição de 1988 voltouse a fixar a idade mínima de trabalho do menor para 14 anos de idade, abrindo-se exceção para o trabalho para aprendizes, ademais, proibiu-se o trabalho de menores de 18 anos de idade em locais perigosos, insalubres e no turno da noite, e determinou-se a proibição de diferenças salariais, de exercício de função e de critérios de admissão por motivo de idade.

No ano de 1990, foi instituído o Estatuto da Criança e do Adolescente (ECA) por meio da Lei n. 8.069 de 13 de julho, dedicando um capítulo específico ao Direito à profissionalização e à proteção ao trabalho do menor e reafirmando a idade mínima de trabalho em 14 anos exceto na condição de aprendiz. No entanto, em 1998, a Emenda Constitucional n. 20, alterou o dispositivo constitucional (art. $7^{\circ}$, XXXIII) e estabeleceu a idade mínima de trabalho, dispondo de modo diverso ao apresentado no ECA, ao qual se colaciona:

XXXIII - proibição de trabalho noturno, perigoso ou insalubre a menores de dezoito e de qualquer trabalho a menores de dezesseis anos, salvo na condição de aprendiz, a partir de quatorze anos (BRASIL, 1990).

Além da proteção expressa com relação ao trabalho da criança e do adolescente, a Constituição ainda elenca o dever que a família tem de protegê-los juntamente com a sociedade e com o Estado (art. 227, CF), sendo essa proteção alcançada inclusive no que tange o trabalho. Conforme expõem Machado e Souza (2015, p. 14), “a proteção constitucional contra a exploração do trabalho infantil está integrada aos pressupostos dos limites de idade mínima para o trabalho previsto na Convenção 138 da OIT, que desde a sua ratificação tem suas regras alçadas ao status de direito fundamental".

A Convenção n. 138 da OIT foi aprovada no Brasil por meio do Decreto Legislativo n. 179 em 14 de dezembro de 1999 e sua ratificação ocorreu em 28 de junho de 2001, promulgandose em 15 de fevereiro de 2002 pelo Decreto n. 4.134 vem tratar sobre a idade mínima para admissão. A Convenção sugere uma idade mínima de 15 anos e estabelece que os países devam adotar limites básicos de idade para o trabalho (OIT, 1976). Com isso posto, se adentra na questão de ter o menor uma proteção integral, visto que "[...] é uma pessoa em desenvolvimento - físico, mental, moral, espiritual e social - e detentora de direitos da personalidade inerentes à sua condição humana em formação" (ALVARENGA, 2015, p. 61).

\begin{abstract}
A teoria da proteção integral estabeleceu-se como necessário pressuposto para a compreensão do Direito da Criança e do Adolescente no Brasil contemporâneo. As transformações estruturais no universo político consolidadas no encerrar do século XX contrapuseram duas doutrinas de traço forte, denominadas da situação irregular e da proteção integral. Foi a partir desse momento que a teoria da proteção integral se tornou referencial paradigmático para a formação de um substrato teórico constitutivo do Direito da Criança e do Adolescente no Brasil (CUSTÓDIO, 2008, p. 22).
\end{abstract}

O princípio da proteção integral decorre do entendimento de que os direitos da criança e do adolescente devem ser alcançados de forma primeira, por sua família, sociedade e Estado, conforme previsto em nossa Carta Magna e também em Convenções Internacionais, como extraído do art. $3^{\circ}, 1$, da Convenção Internacional sobre os Direitos da Criança, promulgada pelo Brasil em 21 de novembro de 1990 por meio do Decreto n. 99.710. Sendo assim, "o reconhecimento dos direitos fundamentais à criança e ao adolescente trouxe consigo o princípio da universalização, segundo o qual os direitos do catálogo são susceptíveis de 
reivindicação e efetivação para todas as crianças e adolescentes" (CUSTÓDIO, 2008, p. 32), sem distinção de sexo, cor, idade, credo etc.

A proteção é integral e estendida a todas as crianças em todos os momentos de sua formação, e não se permite que exceções sejam reconhecidas de modo a colocar as crianças para exercer qualquer tipo de trabalho, até porque o trabalho infantil prejudica o desenvolvimento físico e psicossocial da criança e do adolescente, além de afrontar direitos humanos inerentes a todos, como educação, saúde e segurança.

Buscando alcançar essa proteção máxima às crianças e adolescentes, se utiliza fundamentos internacionais como a Convenção n. 182 da OIT, promulgada pelo Brasil em 12 de setembro de 2000 pelo Decreto n. 3.597, que trouxe a Proibição das piores formas de trabalho infantil e ações imediatas para a sua eliminação. A Convenção estabelece que menor é aquele com menos de 18 anos de idade e traz, em seu art. $3^{\circ}$ :

Artigo $3^{\circ}$ - Para os fins desta Convenção, a expressão as piores formas de trabalho infantil compreende:

a) todas as formas de escravidão ou práticas análogas à escravidão, como venda e tráfico de crianças, sujeição por dívida, servidão, trabalho forçado ou compulsório, inclusive recrutamento forçado ou obrigatório de crianças para serem utilizadas em conflitos armados;

b) utilização, demanda e oferta de criança para fins de prostituição, produção de pornografia ou atuações pornográficas;

c) utilização, recrutamento e oferta de criança para atividades ilícitas, particularmente para a produção e tráfico de entorpecentes conforme definidos nos tratados internacionais pertinentes;

d) trabalhos que, por sua natureza ou pelas circunstâncias em que são executados, são suscetiveis de prejudicar a saúde, a segurança e a moral da criança (Grifo nosso) (OIT, 1999).

Contudo, apesar de toda legislação nacional e internacional - a que se menciona, a justiça brasileira tem feito concessões para $o$ trabalho infantil de modo a assegurar a cultura de alguns povos, como os indígenas, que tem em seu Estatuto (Lei n. 6001/73) que:

Art. $1^{\circ}$ Esta Lei regula a situação jurídica dos índios ou silvícolas e das comunidades indígenas, com o propósito de preservar a sua cultura e integrálos, progressiva e harmoniosamente, à comunhão nacional.

Parágrafo único. Aos índios e às comunidades indígenas se estende a proteção das leis do País, nos mesmos termos em que se aplicam aos demais brasileiros, resguardados os usos, costumes e tradições indígenas, bem como as condições peculiares reconhecidas nesta Lei (BRASIL, 1973).

Ainda na presente legislação, encontra-se no capítulo IV - das condições de trabalho, que o indígena trabalhador não poderá sofrer discriminação para com outros que laboram, sendo-lhes garantido todos os direitos constantes na legislação trabalhista e previdenciária (art. 14, caput). No entanto, ao mesmo tempo em que a legislação preza pela garantia da igualdade nas relações de trabalho e pela proteção do índio, ela autoriza tratamento diferenciado para que se preserve os usos e costumes da comunidade a qual o índio pertence (art. 14, parágrafo único).

Com base nisso que se garantiu uma liminar na Ação Civil Pública n. 500170771.2012.404.7202 requerida pelo Ministério Público Federal de Santa Catarina para que o Instituto Nacional de Seguro Social (INSS) pagasse as indígenas menores de 16 anos saláriomaternidade, pois estas já laboravam desde cedo em atividades artesanais e na agricultura. Sendo assim, aquele que deveria agir como fiscal da lei e protetor da criança e do adolescente, passa para o outro lado e orienta o INSS a conceder benefícios para as menores, pois o trabalho das crianças indígenas é uma realidade cultural que não pode ser modificada.

Nota-se que não está em voga a discussão de ter ou não a criança ou adolescente indígena direito ao salário maternidade, mas sim, a existência de precedente que estabelece como normal o trabalho da criança indígena gerando assim benefícios previdenciários, mesmo tendo 
ela menos do que a idade mínima estabelecida na Constituição Federal para o trabalho.

De acordo com a Unicef (2009) "ao longo dos últimos anos [...] inúmeros estudos indicam ampla negligência no cumprimento dos direitos de crianças de minorias e de populações indígenas", o que leva a Organização a ter uma grande preocupação com o que a cultura está a fazer com as crianças e adolescentes que hoje estão sob a guarida da proteção integral, sendo no Brasil, dever da família, da sociedade e do Estado garantir que elas se desenvolvam de forma digna, independentemente de sua etnia, cor, idade, religião etc.

A criança tem a proteção integral. No entanto, dados apontam para o favorecimento cultural em detrimento da máxima proteção infantil e é com base nisso que adentramos no próximo capítulo, com o intuito de estabelecer critérios conceituais da cultura que explicam que nossas tradições, origens e costumes servem de base para aprendermos e que não devemos seguir aquilo que está em desacordo com a realidade social existente, no caso a permissividade do trabalho das crianças indígenas, pessoas humanas com uma cultura diferente, mas que ao mesmo tempo merecem que lhes sejam alcançadas ampla dignidade em todas as idades de sua vida, a começar por sua infância.

\section{O TRABALHO DAS CRIANÇAS INDÍGENAS COM BASE NA CULTURA DA COMUNIDADE}

De modo geral, o trabalho do povo indígena encontra-se inserido na proteção jurídica das normas laborais como os demais trabalhadores, todavia, com algumas características peculiares que respeitem a legislação especial relativa aos indígenas, sem, contudo, excluí-lo ou discriminá-lo frente à proteção legal com base na sua origem sob pena de violação do texto Constitucional (LIMA
FILHO, [s.a.]).

Apesar dessa consciência protetiva, o que se observa é que as crianças indígenas continuam a trabalhar como uma forma de interagir com o grupo em que estão inseridas e como modo de agregar maior renda aos seus grupos familiares para suprir as necessidades existentes. Contudo, o trabalho da criança indígena está em desacordo com o que é estabelecido na Constituição Federal, ou seja, de que somente maiores de 16 anos poderiam exercer labor, salvo na condição de aprendiz, desde os 14 anos de idade.

No entanto, as crianças indígenas começam a laborar desde muito cedo ajudando na agricultura familiar e também na elaboração de peças artesanais que serão destinadas à venda, ou até mesmo, como se pode acompanhar nas ruas nos dias atuais, as próprias crianças exercem a função de vendedoras dos produtos artesanais por elas fabricados.

Em uma Ação Civil Pública (500626870.2014.404.7105/RS), ajuizada recentemente pelo Ministério Público Federal, para que se garanta o auxílio-maternidade as indígenas menores de 16 anos, o Juiz Federal que analisou o caso diz: "[...] devemos, por respeito aos costumes e tradições dos povos indígenas, tratar esses desiguais de forma desigual", garantindolhes o alcance ao estabelecido no art. 231 da Constituição Federal, do qual se retira que:

Art. 231. São reconhecidos aos índios sua
organização social, costumes, línguas, crenças e
tradições, e os direitos originários sobre as terras
que tradicionalmente ocupam, competindo à
União demarcá-las, proteger e fazer respeitar todos
os seus bens (BRASIL, 1988).

Ainda, continua em sua decisão o Juiz Federal, expondo e admitindo que nossa Carta Constitucional, ao mesmo tempo que protege a cultura, tradições etc. dos silvícolas estabelece a proteção integral para a criança e ao adolescente, "diante da inexorável constatação de que todos estão sujeitos, em território pátrio, ao mesmo 
ordenamento jurídico, há de se assegurar a máxima efetividade de cada um dos preceitos constitucionais".

No entanto, o que se constata é que a máxima de cada direito fundamental não está sendo alcançada, uma vez que está se deixando prevalecer a cultura dos povos indígenas sem garantir as crianças a dignidade da pessoa humana e a igualdade, princípios constitucionais basilares, e as normas que desses derivam.

Nesse ponto, cabe citarmos o ensinamento de Bauman (2012, p. 81), para quem

por mais de um século, as culturas foram definidas basicamente como tecnologias de discriminação e distinção, fábricas de diferenças e oposições. Mas o diálogo e a negociação também são fenômenos culturais - e como tal ganham, em nossa era de pluralidade, uma importância crescente, talvez decisiva. A construção pragmática a que se dá o nome de "humanidade" é também um projeto cultural, um empreendimento que não está fora do alcance da capacidade cultural humana. Podese encontrar ampla afirmação de que assim é em nossa experiência comum da vida cotidiana. Afinal, conviver, conversar uns com os outros e negociar com sucesso soluções mutuamente satisfatórias para problemas comuns são a norma dessa experiência, não a exceção.

Dessa forma, ao analisarmos as lições do autor, podemos entender que em tempos remotos a cultura tinha sim o condão de qualificar o ser humano, impondo-lhe distinções e até mesmo discriminando certos povos em face de outros, para que se definissem as pessoas em classes sociais e com base em anseios culturais. Mas o que significa essa tal "cultura" para que seja possível estabelecer diferentes povos por meio dela?

Não encontramos hoje uma unanimidade com relação ao conceito de cultura, sendo que, se adota, como o conceito mais simples para a palavra cultura, aquele estabelecido por Edward Tylor no século XIX. Essa definição continua na atualidade a ser estudada por diversos antropólogos que buscam aprofundar para compreender de uma melhor forma o comportamento de toda a sociedade. Assim,

o significado mais simples desse termo afirma que cultura abrange todas as realizações materiais e os aspectos espirituais de um povo. Ou seja, em outras palavras, cultura é tudo aquilo produzido pela humanidade, seja no plano concreto ou no plano imaterial, desde artefatos e objetos até ideias e crenças. Cultura é todo complexo de conhecimentos e toda habilidade humana empregada socialmente. Além disso, é também todo comportamento aprendido, de modo independente da questão biológica (SILVA, 2009, p. 85).

Visto assim, a cultura pode estar sempre em transformação além de estar sempre em interação para com outras, uma vez que vivemos em um mundo onde prospera a diversidade cultural. Cabe ressaltar que tal premissa poderá ser mais observada naquele grupo de índios considerados integrados ou em vistas de integração (art. 4, Lei n. 6.001/73) por já estarem inseridos ou muito próximos dessa em uma comunidade nacional, enquanto que, os índios considerados isolados ainda não tiveram nenhum contato com o meio externo a sua comunidade, uma vez que muitas vezes não são nem conhecidos na comunidade nacional.

Ainda, de acordo com Bauman, na atualidade (2013, p. 38) "“...] as relações culturais não são mais verticais, mas horizontais; nenhuma cultura pode exigir ou ter direito à subserviência, a humilhação ou à submissão a qualquer outra simplesmente em decorrência de uma presumida superioridade ou de um 'caráter progressivo",, o que nos faz refletir no enfoque do presente texto de que a cultura indígena, quando estiver prejudicando o seu próprio povo, não poderá ser aceita.

Nesse sentido, as crianças que laboram para ajudar a prover o sustento de toda comunidade estão sendo violadas em sua dignidade e no caráter fundamental de serem protegidas pela família, sociedade e Estado. Deve ocorrer o diálogo para tentar resolver a 
situação e o Estado, como criador de Políticas Públicas, instituir condições adequadas as famílias indígenas para que o trabalho da criança não seja fundamental para o equilíbrio econômico financeiro familiar e da comunidade.

$\mathrm{O}$ fechamento da comunidade com base na cultura cria muros instransponíveis para com outros membros da sociedade que a rodeiam, contudo, deve-se entender que essa teórica segurança que a comunidade cria por manter a distância de outras comunidades acaba por se tornar sua própria inimiga ao ponto que, deixa de garantir direitos inerentes aos seus próprios formadores (BAUMAN, 2003).

\begin{abstract}
Diferenças culturais profundas ou irrisórias, visíveis ou quase despercebidas, são usadas na frenética construção de muralhas defensivas e de plataformas de lançamento de mísseis. "Cultura" vira sinônimo de fortaleza sitiada, e numa fortaleza sitiada os habitantes têm que manifestar diariamente sua lealdade inquebrantável e abster-se de quaisquer relações cordiais com estranhos. A "defesa da comunidade" tem que ter precedência sobre todos os outros compromissos. Sentar-se à mesa com "estranhos", estar em sua companhia nos mesmos lugares, para não falar em enamorar-se ou casar fora dos limites da comunidade, são sinais de tradição e razões para ostracismo e degredo. Comunidades assim construídas viram expedientes que objetivam principalmente a perpetuação da divisão, da separação e do isolamento (BAUMAN, 2003, p. 127).
\end{abstract}

Para completar esse entendimento cabe destacar a Declaração Universal dos Direitos dos Povos Indígenas da qual se extraí que apesar de os povos indígenas serem livres para se relacionar com o Estado (parte 1.1 parágrafos operativos) ainda, de acordo com a parte 1.2 dos parágrafos operativos "os povos indígenas têm o direito ao pleno e efetivo desfrute de todos os direitos humanos e liberdades fundamentais reconhecidos na Carta das Nações Unidas e outros instrumentos internacionais de direitos humanos". Ademais, "os povos indígenas têm o direito de serem livres e iguais a todos os outros seres humanos em dignidade e direitos, e de serem livres de distinção ou discriminação adversa de qualquer tipo baseada em sua identidade indígena", de acordo com a parte 1.3 da referida Declaração.

Sendo assim, se reconhece que aos indígenas devem ser garantidos e alcançados de forma concreta todos os direitos inerentes a qualquer ser humano, não sendo a cultura $o$ fundamental empecilho do desenvolver da comunidade fora de seu ambiente isolado.

No entanto, com a barreira cultural criada, a identidade dos povos indígenas continua a ser formada como seres humanos diferentes dos demais, que não merecem ter a garantia de uma infância plena e saudável, mas sim que devem estar no campo de trabalho de modo a estar junto com seus pais e com a comunidade na busca isolada de condições de sobrevivência. A identidade física dessas crianças vai se formar como única e exclusivamente pertencente a comunidade em que estão inseridas, e, assim, “[...] a ideia de 'ter uma identidade' não vai ocorrer às pessoas enquanto o 'pertencimento' continuar sendo o seu destino, uma condição sem alternativa" (BAUMAN, 2005, p. 17).

Além do que, utilizando-se da Declaração Universal dos Direitos Humanos temos no art. 1": "Todos os seres humanos nascem livres e iguais em dignidade e em direitos. Dotados de razão e de consciência, devem agir uns para com os outros em espírito de fraternidade."

Se todos são iguais em direitos e obrigações não podemos permitir que o trabalho das crianças indígenas seja considerado aceitável de modo a garantir o respeito a cultura desse povo. Se assim for, teremos que respeitar e aceitar a mutilação feminina com base na cultura de determinados países, como ocorre nas sociedades africanas e em algumas partes da Ásia e do Oriente Médio. A comparação pode ser um tanto exagerada, contudo, o que se quer demonstrar é que a mutilação física causada na mulher pode ser tão nefasta como a mutilação 
psicológica que é causada na criança indígena que trabalha, enquanto outras crianças não estão submetidas a essa cultura brincam e não dedicam seu esforço para completar a renda familiar.

\begin{abstract}
A cultura é singularmente humana no sentido de que só o homem, entre todas as criaturas vivas, é capaz de desafiar sua realidade e reivindicar um significado mais profundo, a justiça, a liberdade e o bem - seja ele individual ou coletivo. Assim, normas e ideias não são relíquias de um pensamento metafísico pré-racional que deixa o homem cego às realidades de sua condição. Pelo contrário, elas oferecem a única perspectiva a partir da qual essa condição é vista como a realidade humana e adquire dimensões humanas (BAUMAN, 2012, p. 302).
\end{abstract}

Se a situação do trabalho infantil indígena fosse algo considerado adequado, autoridades não precisariam se reunir para criar estratégias de erradicação dessa prática que explora a criança com base justificativa na cultura. No ano de 2010 representantes de 18 países se reuniram na Colômbia para discutir estratégias para quebrar o ciclo de exploração econômica das crianças. Dados da OIT e das Nações Unidas (NU) apontavam até 2013 que no mundo eram cerca de 168 milhões de crianças, com idade entre 5 e 17 anos, que laboravam, das quais, 85 milhões em condições insalubres e perigosas, sendo que parte desse total, eram crianças indígenas (ABRAMO, 2013).

Segundo consta no Plano de Prevenção e Erradicação do Trabalho Infantil e Proteção ao Adolescente Trabalhador (2011-2015), “as pesquisas da PNAD revelam a persistência de um "núcleo duro" no trabalho infantil, composto por crianças e adolescentes no trabalho familiar não remunerado na agricultura e nas atividades informais urbanas" (BRASIL, 2011), setor em que se qualificam o trabalho das crianças indígenas. Relata Nascimento e Costa (2015/2016) casos de trabalho infantil indígena descoberto em atividades de extrativismo no Estado de Roraima, no labor em canaviais em
Mato Grosso do Sul, e ainda, entre outros casos, a exploração da mão de obra infantil indígena em hotéis do Estado do Amazonas.

Falta um plano de política pública que seja específico para a erradicação do trabalho infantil indígena visto a diversidade cultural apresentada, sendo compreensível que se respeite a cultura existente dentro da comunidade ao mesmo tempo em que se garanta a proteção integral para essas crianças, do mesmo modo em que se estabelece para as demais. Não se pode admitir, conforme ressalta Machado (2011) que as diferenças advindas de outra cultura autorizem formas discriminatórias de proteção à essas crianças ou a qualquer outro indígena que labore fora do seu grupo.

Ademais, cabe retirar o pensamento ideológico dos povos indígenas, assim como de toda a sociedade, de que o trabalho é enobrecedor de modo que seja necessário aprendê-lo desde cedo e que colocar a criança indígena para auxiliar nos trabalhos de toda a comunidade é uma forma cultural aprendida e passada de geração para geração fazendo com que aquele ser humano continue a fazer parte daquele meio de forma completa.

\footnotetext{
Ideias que apensa ocultam mais uma forma perversa de violência contra a criança são apresentadas nesses mitos culturais e estão estruturadas sobre a lógica menorista e, por isso, são incompatíveis com a perspectiva dos direitos humanos na atualidade. É deste modo que o discurso do "trabalho enobrecedor" representa uma visão discriminatória, denotando que a marginalidade já estaria inserida culturalmente nas populações mais pobres, mitos que encontram raízes no ultrapassado pensamento positivista da Criminologia. Neste sentido, o trabalho cumpriria um papel disciplinador, sob a ordem da moral idealizada, como forma de evitar a ociosidade e seus correspondentes "desejos do mal" (MACHADO; SOUZA, 2015, p. 19).
}

Não é fácil erradicar essa prática nefasta para as crianças indígenas, uma vez que arraigado na cultura desse povo está a permissividade de que devem os pequenos 
aprenderem e colaborarem com a comunidade desde cedo, tanto na agricultura, como no processo artesanal.

Contudo, de acordo com Sousa ([s.a], p. 2), "a pobreza, intrinsecamente relacionada com a formação educacional deficitária, reside sempre na raiz da utilização da mão de obra dos pequenos em detrimento do labor dos adultos", fator este que afeta diretamente as comunidades indígenas que se encontram sempre abaixo da considerada linha de pobreza. Também, poderia se dizer que o contato entre o homem branco e os indígenas oferece a esse último grupo possibilidades de desenvolvimento, mas que é fruto da exploração do trabalho de suas crianças (NASCIMENTO; COSTA, 2015-2016).

Deve-se, dessa forma, estabelecer diretrizes para a erradicação do trabalho infantil que visem garantir a estas famílias renda e emprego, "[...] tendo em vista que a pobreza é um dos principais fatores que as levam a inserir seus filhos no trabalho e, portanto, a renda levada pelas crianças e pelos adolescentes tem um peso importante para casa (MACHADO; SOUZA, 2015, p. 21)".

Nesse sentido, o que se constata é que a questão vai além da estratégia cultural de um povo, mas sim de uma fonte de sobrevivência, o que nos leva a fazer outro comparativo, que se a questão deve ser contornada levando-se em conta o rendimento familiar, se uma família estivesse com problemas financeiros a ponto de se perderem vidas devido à falta de mantimentos, qualquer criança poderia trabalhar de forma a garantir a existência da sua família.

No entanto, não é dessa forma que devemos pensar, pois cabe ao Estado fortalecer as Políticas Públicas que visem a melhora das condições de vida dessas pessoas, não sendo viável que se permita o trabalho infantil de modo a sobrevivência em um mundo em que existe a má distribuição de renda.

Completando tal entendimento destaca
Reis (2015, p. 136) que

a exploração do trabalho de crianças e de adolescentes com idade inferior ao mínimo legal configura-se como trabalho infantil e é totalmente vedada pelo ordenamento jurídico brasileiro. A proteção integral e a prioridade absoluta, consagradas pela Constituição Federal de 1988 e que sustentam o Direito da Criança e do Adolescente, ensejam a observância das normas protetivas.

Sendo assim, não há que se falar que para respeitar a cultura advinda de muito tempo nas comunidades indígenas deva ser permitido o trabalho das crianças indígenas, pois estas também são humanas e dignas de terem respeitados e alcançados todos os direitos e garantias de proteção integral a elas inerentes, devendo advir da família, da sociedade e do Estado a máxima proteção.

Deve-se voltar ao antigo entendimento da expressão "cultura" na qual se tinha, como destaca Bauman (2013, p. 12), que

segundo o conceito original, a "cultura" seria um
agente da mudança do status quo, e não de sua
preservação; ou, mais precisamente, um
instrumento de navegação para orientar a evolução
social rumo a uma condição humana universal. O
propósito inicial do conceito de "cultura" não era
servir como registro de descrições, inventários e
codificações da situação corrente, mas apontar um
objetivo e uma direção para futuros esforços. O
nome "cultura" foi atribuído a uma missão
proselitista, planejada e empreendida sob a forma
de tentativas de educar as massas e refinar seus
costumes, e assim melhorar a sociedade e
aproximar "o povo", ou seja, os que estão na "base
da sociedade", daqueles que estão no topo. A
"cultura" era associada a um "feixe de luz" capaz
de "ultrapassar os telhados" das residências rurais e
urbanas para atingir os recessos sombrios do
preconceito e da superstição que, como tantos
vampiros (acreditava-se), não sobreviveriam
quando expostos à luz do dia.

No entanto, se transformou a cultura em arma contra aqueles que são o futuro de um mundo melhor e os colocou a trabalhar em nome da tradição e do costume de um povo, dizendo- 
lhes que o trabalho enobrece e que é preferível que as famílias fiquem juntas e todos trabalhem para manter essa comunidade, não havendo distinção do trabalho entre os seus membros. Todos devem participar da formação da vida financeira, até mesmo aqueles que ainda não possuem total discernimento para a prática do labor, fato este que coloca as crianças indígenas em desamparo frente a proteção integral que elas têm direito, o simples direito de serem crianças e não se preocuparem com a vida adulta, pelo menos por enquanto.

\section{CONCLUSÃO}

Como se pode observar no decorrer do texto, o princípio da igualdade deve ser alcançado a todos, sem distinção, contudo, devese se tratar da mesma forma os iguais $\mathrm{e}$ desigualmente os desiguais no nível da sua desigualdade. Nesse sentido, os povos indígenas, devem ser tratados de forma desigual, mas não de modo discriminatório e sim para que se atinja de maneira plena e igual aos demais os direitos de seres humanos a eles inerentes. A diferença que existe entre as culturas não pode ser levada ao cabo de deixar que os povos indígenas sofram e sejam violentados em seus direitos.

Essa igualdade deve ser alcançada as crianças indígenas que devem receber a máxima proteção instituída na Constituição brasileira de 1988, de onde se extraí que é incumbência da família, da sociedade e do Estado garantir a proteção integral da criança e do adolescente. Tendo a Carta Maior como pano de fundo, temse que o trabalho infantil é proibido. Tal premissa, com base no princípio da igualdade, deverá ser alcançada a todas as crianças na qual se incluiu as crianças indígenas.

Sendo assim, com base no princípio da igualdade e da proteção integral da infância, as crianças indígenas não podem ser exploradas e colocadas para desenvolver o trabalho inerente aos adultos. A justificativa dessa agressão a criança alcança pano de fundo na cultura dos povos indígenas; no entanto, como podemos observar, a conceituação de cultura está sendo utilizada como uma forma de isolamento e manutenção de comunidades sem o convívio com o restante da sociedade. O conceito atual de cultura, contudo, requer que utilizemos de experiências do passado para interagir no meio social e não para nos isolarmos e levantarmos muros instransponíveis.

A cultura que apregoa que a criança indígena deve trabalhar juntamente com os seus familiares, na agricultura ou na fabricação de artesanato, tira dessa a possibilidade de lhe ser alcançada a máxima proteção estabelecida no texto constitucional, ademais, deve ser pelo fato de não se optar pelo confronto com a cultura que pouco se acha relativo a um assunto tão importante. Índices oficiais e internacionais apontam para a continuidade do trabalho, inclusive o indígena, mas pouco é divulgado sobre meios de inibir ou erradicar tal prática abusiva na sociedade do século XXI.

Dessa forma, a partir do que foi exposto é possível concluir que o trabalho infantil indígena existe e é acentuado, de maneira equivocada, em uma cultura que ao invés de ajudar aqueles que a praticam, impõem aos seus formadores restrições e garantias de uma vida plena e saudável juntamente com outros membros da sociedade. Sendo assim, não são os iguais que se isolam, mas sim aqueles que se "acham" desiguais e acabam com isso perdendo direitos a ele inerentes e causando prejuízo aos demais que compõe determinada comunidade.

Temos que acabar, erradicar com o trabalho infantil, inclusive no meio indígena, pois, na falta de recursos financeiros básicos de sobrevivência, cabe ao Estado estabelecer medidas favoráveis e que promovam uma melhor e igual distribuição de renda, e não nossas crianças, o futuro de uma nova geração, isso 
torna-se inevitável em uma sociedade que luta pela integração e união de todo o seu povo, cumprindo-se e alcançando a cada um a dignidade inerente.

O ônus de garantir a renda de uma comunidade não pode ser colocada nas mãos de uma criança, isso é retroceder e voltar para tempos passados em que o trabalho infantil acontecia de forma livre e desenfreada nas "barbas" do Estado e sem que esse tomasse frente para erradicar com tal prática. A luta pela integração do povo indígena no meio social serve para que esses possam se desenvolver e tenham uma vida digna, mas não para que adultos e crianças indígenas sejam explorados.

\section{REFERÊNCIAS}

ABRAMO, Laís. Panorama mundial do trabalho infantil e a experiência brasileira. In.: Fórum Mundial de Direitos Humanos. Brasília, dez. 2013. Disponível em: $<$ http://www.oitbrasil.org.br/sites/default/files/topic/gender/doc/2013\%20apresenta\%C3\%A7\%C3\% A3o\%20ti\%20forum\%20direitos\%20humanos\%2012dez13\%20vr_1_1119.pdf $>$. Acesso em: 10 jul. 2016.

ALVARENGA, Rúbia Zanotelli de. A abolição efetiva do trabalho infantil: Convenções 138 e 182 da OIT. Justiça do Trabalho, ano 32, n. 382, out. 2015. Porto Alegre: HS Editora, 2015.

BARROS, Alice Monteiro de. Curso de direito do trabalho. 7. ed. São Paulo: LTr, 2011.

BAUMAN, Zygmunt. Comunidade: a busca por segurança no mundo atual. Tradução Plínio Dentzien. Rio de Janeiro: Zahar, 2003.

- Identidade: entrevista a Benedetto Vecchi. Tradução Carlos Alberto Medeiros. Rio de Janeiro: Zahar, 2005.

Zahar, 2012.

Ensaios sobre o conceito de cultura. Tradução Carlos Alberto Medeiros. Rio de Janeiro:

. A cultura no mundo líquido moderno. Tradução Carlos Alberto Medeiros. 1. ed. Rio de Janeiro: Zahar, 2013.

BRASIL. Constituição (1988). Constituição da República Federativa do Brasil. Disponível em: $<$ http://www.planalto.gov.br/ccivil_03/constituicao/constituicaocompilado.htm>. Acessado em: 10 jul. 2016.

. Lei n. 6.001, de 19 de dezembro de 1973. Dispõe sobre o Estatuto do Índio. Disponível em: $\overline{<\mathrm{http}: / / w w w . p l a n a l t o . g o v . b r / c c i v i l \_03 / 1 e i s / L 6001 . h t m>. ~ A c e s s a d o ~ e m: ~} 10$ jul. 2016.

. Lei n. 8.069, de 13 de julho de 1990. Dispõe sobre o Estatuto da Criança e do Adolescente e dá outras providências. Disponível em: <http://www.planalto.gov.br/ccivil_03/leis/L8069.htm>. Acessado em: 10 jul. 2016.

. Decreto n. 99.710, de 21 de novembro de 1990. Promulga a Convenção sobre os Direitos da 
Criança. Disponível em: <http://www.planalto.gov.br/ccivil_03/decreto/1990-1994/D99710.htm>. Acessado em: 10 jul. 2016.

. Plano Nacional de Prevenção e Erradicação do Trabalho Infantil e Proteção do Adolescente Trabalhador. 2. ed. Brasília: Ministério do Trabalho e Emprego, 2011. Disponível em: $<$ http://www.oit.org.br/sites/default/files/topic/ipec/pub/plan-prevencao-trabalhoinfantilweb_758.pdf $>$. Acessado em: 10 jul. 2016.

CANOTILHO, José Joaquim Gomes. Direito Constitucional. 7. ed. Coimbra: Almedina, 2014.

CUSTÓDIO, André Viana. A exploração do trabalho infantil doméstico no Brasil contemporâneo: limites e perspectivas para sua erradicação. 2006. 282 f. Tese (Doutorado em Direito) - Universidade Federal de Santa Catarina, Florianópolis/SC, 2006. Disponível em: $<$ http://www.dominiopublico.gov.br/download/teste/arqs/cp007202.pdf>. Acessado em: 27 jan. 2016.

. Teoria da proteção integral: pressuposto para compreensão do direito da criança e do adolescente. 2008.

p. 22-43. Disponível

em: $<$ http://online.unisc.br/seer/index.php/direito/article/viewFile/657/454. . . Acessado em: 12 dez. 2015.

LEITE, Carlos Henrique Bezerra. Direitos humanos. 2. ed. Rio de Janeiro: Lumen Juris, 2011.

LIMA FILHO, Francisco da C. Contrato de trabalho dos indígenas: requisitos, validade e eficácia. [s.a]. Disponível

em:

$<\mathrm{http}$ //www.unigran.br/revista_juridica/ed_anteriores/19/artigos/trabalho\%20indigena.pdf $>$. Acesso em: 10 jul. 2016.

MACHADO, Jorge Luis. O trabalhador indígena e o direito à diferença: o caminho para um novo paradigma antropológico no direito laboral. Revista do Tribunal Regional do Trabalho, $3^{\mathrm{a}}$ Região. v. 53, n. 83. Belo Horizonte: jan./jun. 2011. p. 269-283. Disponível em: $<$ http://www.trt3.jus.br/escola/download/revista/rev_83/jorge_luis_machado.pdf $>$. Acesso em: 10 jul. 2016.

MACHADO, Raimar Rodrigues; SOUZA, Ismael Francisco de. A proteção contra a exploração do trabalho infantil e suas dimensões no Brasil. In: MACHADO, Raimar Rodrigues; SOUZA, Ismael Francisco de. (orgs.). Direitos sociais no constitucionalismo contemporâneo: perspectivas do direito do trabalho. Curitiba: Multideia, 2015.

MORAES FILHO, Evaristo de; MORAES, Antonio Carlos Flores de. Introdução ao direito do trabalho. 11. ed. São Paulo: LTr, 2014.

NASCIMENTO, Edmílson Alves do; COSTA, Renilda Aparecida. Indígenas e trabalho infantil: da fronteira étnico-cultural à perspectiva de uma ação institucional diferenciada no Brasil. Argumenta Journal Law, Jacarezinho/PR, n. 23, jul.2015-jan.2016. p. 129-158. Disponível em: $<$ http://seer.uenp.edu.br/index.php/argumenta/article/viewFile/672/pdf_100>. Acesso em: 10 jul. 2016.

NAÇÕES UNIDAS. Declaração Universal dos Direitos Humanos, 10 de dezembro de 1948. Disponível em: <http://www.dudh.org.br/declaracao/>. Acessado em: 10 jul. 2016.

. Convenção sobre os Direitos da Criança, 20 de novembro de 1989. Disponível em: 
$<\mathrm{http}: / /$ www.unicef.org/brazil/pt/resources_10120.htm>. Acessado em: 10 jul. 2016.

. Declaração Universal dos Direitos dos Povos Indígenas, 29 de junho de 2006. Disponível em: <http://www.prefeitura.sp.gov.br/cidade/secretarias/direitos_humanos/conheca_mais_dh/ind ex.php?p=812>. Acessado em: 27 jan. 2016.

ORGANIZAÇÃO INTERNACIONAL DO TRABALHO. História. Disponível em: $<$ http://www.oitbrasil.org.br/content/hist\%C3\%B3ria>. Acessado em: 10 jul. 2016.

. Convenção n. 111, de 15 jun. 1960. Discriminação em matéria de emprego e ocupação. Disponível em: <http://www.oitbrasil.org.br/node/472>. Acessado em: 10 jul. 2016.

. Convenção n. 138, de 19 jun. 1976. Idade mínima para admissão. Disponível em: $<$ http://www.oitbrasil.org.br/node/492>. Acessado em: 10 jul. 2016.

. Convenção n. 182, de $1^{\circ}$ jun. 1999. Convenção sobre proibição das piores formas de trabalho infantil e ação imediata para sua erradicação. Disponível em: <http://www.oitbrasil.org.br/node/518>. Acessado em: 10 jul. 2016.

PORTUGAL. Directiva 2000/78/CE do Conselho, de 27 de novembro de 2000, que estabelece um quadro geral de igualdade de tratamento no emprego e na actividade profissional. Disponível em: $<$ http://eur- lex.europa.eu/LexUriServ/LexUriServ.do?uri=CELEX:32000L0078:pt:HTML>. Acessado em: 10 jul. 2016.

RAWLS, John. Uma teoria da justiça. Tradução Jussara Simões. 3. ed. São Paulo: Martins Fontes, 2008.

REIS, Suzéte da Silva. Ações e estratégias de políticas públicas para o enfrentamento da exploração do trabalho infantil nos meios de comunicação no marco da teoria da proteção integral aos direitos da criança e do adolescente. 2015. 264 f. Tese (Doutorado em Direito) - Universidade de Santa Cruz do Sul, Santa Cruz do Sul/RS, 2015. Disponível em: $<$ http://repositorio.unisc.br/jspui/bitstream/11624/831/1/Suzete-

Tese\%20vers\%C3\%A3o\%20final.pdf>. Acessado em: 27 jan. 2016.

RIO GRANDE DO SUL. Justiça Federal. Ação Civil Pública n. 5006268-70.2014.404.7105,da Seção Judiciária do Rio Grande do Sul, $2^{\text {a }}$ Vara Federal se Santo Ângelo. Autor: Ministério Público Federal. Réu: Instituto Nacional do Seguro Social - INSS. Juiz Federal: Daniel Luersen. 06 fev. 2015. Disponível em: $<$ http://s.conjur.com.br/d1/liminar-concede-indias-guaranis-rs.pdf $>$. Acessado em: 27 jan. 2016.

SANTA CATARINA. Justiça Federal. Ação Civil Pública n. 5001707-71.2012.404.7202, da Seção Judiciária de Santa Catarina, Subseção Judiciária de Chapecó. Autor: Ministério Público Federal. Réu: Instituto Nacional do Seguro Social - INSS. 12 mar. 2012. Disponível em: $<$ http://noticias.pgr.mpf.mp.br/noticias/noticias-do-site/copy_of_indios-eminorias/imprimir?\&UID=a4fffe0d125beaa379bae822366023c7\&keepThis=true \&TB_iframe $=$ true $\&$ height $=400 \&$ width $=700>$. Acessado em: 27 jan. 2016.

SILVA, José Afonso da. Curso de direito constitucional positivo. 37. ed. São Paulo: Malheiros, 2014. SILVA, Kalina Vanderlei. Dicionário de conceitos históricos. 2. ed. São Paulo: Contexto, 2009. 
Disponível em: $<$ https://efabiopablo.files.wordpress.com/2013/04/dicionc3a1rio-de-conceitoshistc3b3ricos.pdf>. Acessado em: 10 jul. 2016.

SOUSA, Maria do Socorro Almeida de. Idade mínima para o trabalho na ordem jurídica brasileira. [s.a]. Disponível em: <http://www.tst.jus.br/documents/2237892/2544819/Artigo+$+\mathrm{Ma} .+$ do + Socorro + Almeida + de + Sousa_Idade $+\mathrm{m} \% \mathrm{C} 3 \%$ ADnima + para $+\mathrm{o}+$ trabalho $>$. Acessado em: 27 jan. 2016.

SOUZA, Ismael Francisco de. A erradicação do trabalho infantil e as responsabilidades do conselho tutelar no município de Florianópolis. 2008. 149 f. Dissertação (Mestrado em Serviços Sociais) Universidade Federal de Santa Catarina, Florianópolis/SC, 2008. Disponível em: $<$ http://livros01.livrosgratis.com.br/cp107950.pdf>. Acessado em: 18 nov. 2015.

SÜSSEKIND, Arnaldo; MARANHÃO, Délio; VIANNA, Segadas; TEIXEIRA, Lima. Instituições de direito do trabalho, v. II. Atualizado por Arnaldo Süssekind e João de Lima Teixeira Filho. 22. ed. São Paulo: LTr, 2005.

UNICEF. A relevância perene da Convenção. 2009. Disponível em: $<$ http://www.unicef.org/brazil/sowc20anosCDC/cap1.html>. Acessado em: 10 jul. 2016.

Recebido em: 10/02/2016

Aceito em: 25/07/2016 
